\title{
Optimal ilio-sacral screw trajectory in paediatric patients : a computed tomography study
}

\author{
Mathilde Gaume, Mohamed Amine Triki, Christophe Glorion, Sylvain Breton, Lofti Miladi \\ From the Orthopaedics Surgery Department, University of Paris, Necker Hospital, Assistance Publique Hopitaux de Paris, \\ Paris, France
}

Pelvic fixation during procedures performed to treat spinal deformities in paediatric patients remains challenging. No computed tomography studies in paediatric have assessed the optimal trajectory of iliosacral screws to prevent screw malposition.

We used pelvic computed tomography from 80 children divided into four groups : females $<10$ and $\geq 10$ years and males $<10$ and $\geq 10$ years. A secure triangular corridor parallel to the upper $S 1$ endplate was delineated based on three fixed landmarks. The optimal screw insertion angle was subtended by the horizontal and the line bisecting the secure corridor. Student's $t$ test was applied to determine whether the optimal screw insertion angle and/or anatomical parameters were associated with age and/or sex.

Mean optimal angle was $32.3^{\circ} \pm 3.6^{\circ}, 33.8^{\circ} \pm 4.7^{\circ}$, $30.2^{\circ} \pm 5.0^{\circ}$, and $30.4^{\circ} \pm 4.7^{\circ}$ in the younger females, younger males, older females, and older males, respectively. The mean optimal angle differed between the two age groups $(p=0.004)$ but not between females and males $(p=0.55)$. Optimal mean screw length was 73.4 $\pm 9.9 \mathrm{~mm}$. Anatomical spinal canal parameters in the transverse plane varied with age $(p=0.02)$ and with sex in the older children $(p=0.008)$, and those in the sagittal plane varied with $\operatorname{sex}(p=0.04)$.

Age affected ilio-sacral screw positioning, whereas sex did not. Several anatomical spinal canal parameters varied with age and sex. These results should help to ensure safe and easy ilio-sacral screw placement within a secure corridor.

Keywords : Ilio-sacral screws ; pelvic fixation ; computed tomography study ; paediatric population.

No benefits or funds were received in support of this study. None of the authors have a conflict of interest.

\section{INTRODUCTION}

Pelvic fixation during procedures performed to treat spinal deformities in paediatric patients remains challenging. Although many techniques have been described, most are associated with high complication rates (1). Ilio-sacral screw fixation is a reliable option but is less often used than other methods due to its technical difficulty.

The Harrington rod and Cotrel-Dubousset instrumentation procedures for neuromuscular scoliosis described over three decades ago included the insertion of an ilio-sacral screw, using a specific

Mathilde Gaume ${ }^{1}, \mathrm{MD}$

- Mohamed Amine Triki ${ }^{1,2}$, MD,

Christophe Glorion ${ }^{1}, \mathrm{MD}, \mathrm{PhD}$,

Sylvain Breton ${ }^{3}, \mathrm{MD}$,

Lofti Miladi ${ }^{1}, \mathrm{MD}$.

${ }^{\prime}$ Orthopaedics Surgery Department, University of Paris, Necker Hospital, Assistance Publique Hopitaux de Paris, Paris, France

${ }^{2}$ Orthopaedic Department, Sahloul Hospital, Université de Sousse, Sousse, Tunisia

${ }^{3}$ Paediatric Radiology Department, University of Paris, Necker Hospital, Assistance Publique Hôpitaux de Paris, Paris, France

Correspondence : M. Gaume, Paediatric Orthopaedic Department, Necker Hospital, 149 rue de Sèvres, 75015 Paris, France. Tel : 033144494000.

E-mail : mathilde.gaume@aphp.fr

- 2021, Acta Orthopædica Belgica. 
connector $(2,3)$. Recent changes in the tool kit have improved the safety and accuracy of iliosacral screw fixation, which can now be performed percutaneously (4). A cannulated screw is inserted percutaneously through an ilio-sacral connector, from the posterior part of the iliac bone to the sacrum, in an oblique posterior-to-anterior direction in order to direct the screw in front of the spinal canal until it reaches the body of S1. The iliosacral connector is fixed on a connector holder and introduced into the sacral bone laterally to the S1 facet and above the posterior S1 foramen (Figure 1). The degree of medial tilt of the connector holder determines the angle of insertion of the ilio-sacral screw in the transverse plane (Figure 2).

Several computed tomography (CT) studies have assessed the optimal trajectory of ilio-sacral screws and other pelvic fixation devices in order to prevent screw malposition, associated with potentially severe injuries. No similar studies in paediatric patients have been published to date.

The main objective of this retrospective study was to use CT scans to determine the optimal angle



Fig, 1. - The entry point of the ilio-sacral connector.

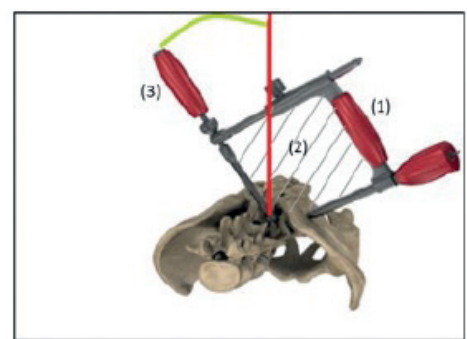

Fig, 2. - Setting of the ilio-sacral screw using a guide (1). The red line is the vertical. The medial tilt of the connector holder (3) determines the angle of screw insertion (in green). The frame of the guide (2) is in a plane parallel to the S1 endplate. of ilio-sacral screw insertion in paediatric patients. We also looked for associations liking age and sex to the values of various anatomical sacral parameters.

\section{MATERIAL AND METHODS}

This single-centre study was conducted in 80 children (aged <16y) who underwent CT of the pelvis between July 2012 and July 2018. We included 20 females younger than 10 years $(\mathrm{F}<10)$, 20 males younger than 10 years $(\mathrm{M}<10), 20$ females aged 10 years or older $(\mathrm{F} \geq 10)$, and 20 males aged 10 years or older $(M \geq 10)$. We stopped identifying patients when we got to 20 patients per group.

CareStreamVue PACS (CareStream Health France SAS, Noisy-le-Grand, France) was used to assess $10-\mathrm{mm}$ slices parallel to the upper $\mathrm{S} 1$ endplate. A senior radiologist and two surgeons

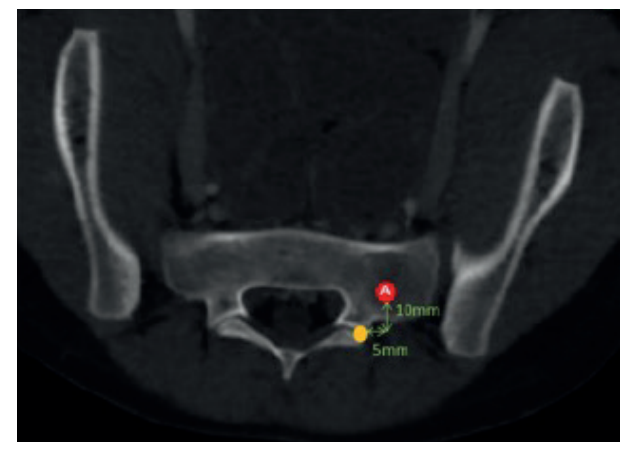

Fig. 3. - Point A is the connector set point, $-5 \mathrm{~mm}$ lateral to the L5-S1 facet joint, and $-10 \mathrm{~mm}$ anterior to the posterior sacral cortex. Lumbo-sacral articular process.



Fig. 4. - Point B is the intersection of lines $\left(\mathrm{x}_{2}\right)$ and $\left(\mathrm{y}_{2}\right) \cdot\left(\mathrm{x}_{1}\right)$ Line tangent to the lateral edge of the spinal canal. $\left(\mathrm{x}_{2}\right)$ Line parallel to, and $5 \mathrm{~mm}$ away from, $\left(\mathrm{x}_{1}\right)$. $\left(\mathrm{y}_{1}\right)$ Line tangent to the anterior edge of the spinal canal. $\left(\mathrm{y}_{2}\right)$ Line parallel to, and $5 \mathrm{~mm}$ away from, $\left(\mathrm{y}_{1}\right)$. 
working independently of one another recorded all CT measurements on two separate occasions (3 months).

The connector set point, designated point A (Figure 3), was located $5 \mathrm{~mm}$ lateral to the L5-S1 facet joint and $10 \mathrm{~mm}$ anterior to the posterior sacral cortex. Line $\mathrm{x}_{2}$ was parallel to, and $5 \mathrm{~mm}$ away from, the tangent to the lateral edge of the spinal canal. Line $\mathrm{y}_{2}$ was parallel to, and $5 \mathrm{~mm}$ away from, the tangent to the anterior edge of the spinal canal.

Point $\mathrm{B}$ was at the intersection of lines $\mathrm{x}_{2}$ and $\mathrm{y}_{2}$ (Figure 4). Point C (Figure 5) was $10 \mathrm{~mm}$ anterior to the most posterior edge of the external iliac bone.

Line $\mathrm{AC}$ anteriorly and line $\mathrm{AB}$ posteriorly delineate a triangular corridor for safe screw insertion through the connector. Remaining within this secure corridor ensures that the screw is not placed in the pelvis or spinal canal. The optimal screw insertion angle was defined as the angle between the horizontal and the plane bisecting the secure corridor (Figure 6).



Fig. 5. - Point $\mathrm{C}$ is $10 \mathrm{~mm}$ anterior to the most posterior edge of the external iliac bone.

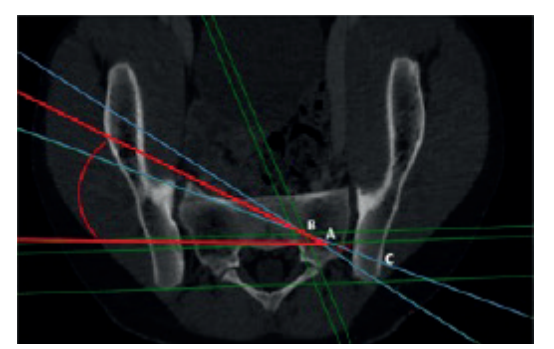

Fig. 6. - Measurement of the optimal direction on CT scan. In blue : the triangular secure corridor. The red arc is the optimal direction defined by the angle between the line bisecting the secure corridor and the horizontal.

\section{Anatomical parameters}

Four anatomical parameters were measured on the CT scans : distance between the most posterior iliac processes (PIP) ; distance between the posterior sacral joints (PSJ); lateral (side-to-side diameter of the spinal canal (LD) ; and antero-posterior diameter of the spinal canal (APD) (Figure 7).

The data were recorded in Excel $^{\circledR} 2008$ (Microsoft, Richmond, WA). All statistical analyses were performed using SPSS $^{\circledR}$ Advanced Statistics 20.0 software (IBM, Armonk, NY). Continuous variables were described as mean \pm SD after verification of distribution normality using Shapiro's test.

To look for potential associations linking age and sex to the optimal screw insertion angle, we conducted separate analysis of the four groups $(\mathrm{F}<10, \mathrm{M}<10, \mathrm{~F} \geq 10$, and $\mathrm{M} \geq 10)$. Student's $t$ test was chosen to identify associations linking each group to mean optimal screw insertion angle. We also compared females to males and younger to older children. Finally, we compared anatomical parameters across the four groups using Student's $t$ test. Values of $p$ lower than 0.05 were considered significant.

The intra- and inter-observer reliability of all measurements was assessed using Spearman's rank test, a $t$ test and the intra-class correlation coefficient (ICC), and the limits of agreement on a Bland-and-Altman plot. Values of $p$ for Spearman's rank correlation and all $t$ tests were considered significant if lower than 0.05 .

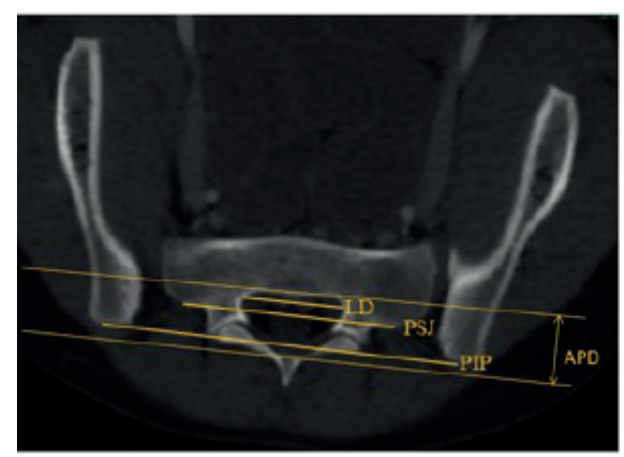

Fig. 7. - Measurement of anatomical parameters on CT scan. PIP : distance between the posterior iliac processes. PSJ : distance between the posterior sacral joints. LD : lateral (sideto-side) diameter of the spinal canal. APD : antero-posterior diameter of the spinal canal. 
Table 1. - Optimal screw insertion angle and screw length in each group by age and sex

\begin{tabular}{|l|c|c|c|c|c|}
\hline \multirow{2}{*}{} & \multirow{2}{*}{$\begin{array}{c}\text { Age, } \\
\text { years mean } \pm \text { SD }\end{array}$} & \multicolumn{3}{|c|}{ Optimal direction } & \multirow{2}{*}{$\begin{array}{c}\text { Screw length, } \\
\text { mean } \pm \text { SD }\end{array}$} \\
\cline { 2 - 5 } & & Min. angle $\left(^{\circ}\right)$ & Max. angle $\left(^{\circ}\right)$ & Mean \pm SD angle $\left(^{\circ}\right)$ & $67.7 \pm 7.2$ \\
\hline $\mathrm{F}<10(\mathrm{n}=20)$ & $8.4 \pm 1.1$ & 24.6 & 39.6 & $32.3 \pm 3,6$ & $71.5 \pm 5.8$ \\
\hline $\mathrm{M}<10(\mathrm{n}=20)$ & $8.0 \pm 1.0$ & 26.5 & 41.0 & $33.8 \pm 4.7$ & $72.2 \pm 8.7$ \\
\hline $\mathrm{F} \geq 10(\mathrm{n}=20)$ & $12.3 \pm 1.7$ & 20.0 & 36.0 & $30.2 \pm 5.0$ & $77.1 \pm 10.6$ \\
\hline $\mathrm{M} \geq 10(\mathrm{n}=20)$ & $11.9 \pm 1.6$ & 22.0 & 37.0 & $30.4 \pm 4,7$ & \\
\hline
\end{tabular}

$\mathrm{F}<10$, females younger than 10 years ; $\mathrm{M}<10$, males younger than 10 years ; $\mathrm{F} \geq 10$, females aged 10 years or older ; M $\geq 10$, males aged 10 years or older.

\section{RESULTS}

Table I reports the mean age and the optimal screw insertion angles and lengths in each group. Table II shows that the mean optimal screw insertion angle differed significantly between the younger and older groups of females and males pooled. In contrast, when the ages were pooled, no difference in the mean optimal screw insertion angle was found between females and males.

Table III compares the values of the main sacral anatomical parameters across the four groups. Significant differences were found only for the mean distance between the two L5-S1 facet joints, which was significantly greater in younger males than in younger females ; and for the sideto-side diameter of the spinal canal, which was

Table 2. - Comparison of optimal screw insertion angle in younger vs. older patients, and in female vs. male.

\begin{tabular}{|l|c|}
\hline & $\begin{array}{c}\text { Optimal direction, }{ }^{\circ}, \\
\text { mean } \pm \mathrm{SD}\end{array}$ \\
\hline $\begin{array}{l}\text { Females and males } \\
<10 \text { years, } \mathrm{N}=40\end{array}$ & $33.1 \pm 4.3$ \\
\hline $\begin{array}{l}\text { Females and males } \\
\geq 10 \text { years, } \mathrm{N}=40\end{array}$ & $30.0 \pm 4.6$ \\
\hline$p$ value $^{\mathrm{a}}$ & 0.004 \\
\hline Females in both age groups, $\mathrm{N}=40$ & $31.1 \pm 4.4$ \\
\hline Males in both age groups, $\mathrm{N}=40^{\mathrm{a}}$ & $31.7 \pm 5.0$ \\
\hline$p$ value $^{\mathrm{a}}$ & 0.55 \\
\hline
\end{tabular}

Table 4. - Comparison of the mean $\pm \mathrm{SD}$ values of the anatomical parameters between the two age groups

\begin{tabular}{|l|c|c|c|}
\hline & $\begin{array}{c}<10 \text { years } \\
(\mathrm{n}=40)\end{array}$ & $\begin{array}{c}\geq 10 \text { years } \\
(\mathrm{n}=40)\end{array}$ & $p$ value $^{\mathrm{a}}$ \\
\hline PIP $(\mathrm{mm})$ & $86.6 \pm 6.8$ & $98.1 \pm 3.3$ & 0.001 \\
\hline PSJ $(\mathrm{mm})$ & $47.9 \pm 4.6$ & $53.9 \pm 6.4$ & 0.001 \\
\hline LD $(\mathrm{mm})$ & $30.8 \pm 3.2$ & $32.3 \pm 3.8$ & 0.02 \\
\hline APD $(\mathrm{mm})$ & $17.1 \pm 2.6$ & $18.7 \pm 3.1$ & 0.09 \\
\hline
\end{tabular}

Student's $t$ test. PIP, distance between the two posterior iliac processes; PSJ, distance between the two posterior sacral joints ; LD, lateral (sideto-side) diameter of the spinal canal ; APD, antero-posterior diameter of the spinal canal.

Table 5. - Comparison of the mean $\pm \mathrm{SD}$ values of the anatomical parameters between females and males

\begin{tabular}{|l|c|c|c|}
\hline & $\begin{array}{c}\text { Females } \\
\mathrm{N}=40\end{array}$ & $\begin{array}{c}\text { Males } \\
\mathrm{N}=40\end{array}$ & $p$ value $^{\mathrm{a}}$ \\
\hline PIP $(\mathrm{mm})$ & $92.7 \pm 4.5$ & $92.2 \pm 4.2$ & 0.44 \\
\hline PSJ $(\mathrm{mm})$ & $49.0 \pm 5.9$ & $53.1 \pm 6.2$ & 0.31 \\
\hline LD $(\mathrm{mm})$ & $30.3 \pm 3.8$ & $32.9 \pm 2.8$ & 0.11 \\
\hline APD $(\mathrm{mm})$ & $17.1 \pm 3.0$ & $18.9 \pm 2.6$ & 0.04 \\
\hline
\end{tabular}

significantly smaller in the older males than in the older females. Comparing the two age groups (Table IV) also identified significant differences, with higher mean values in the older group for the PIP distance, distance between the two L5-S1 facet joints (PSJ distance), and LD. The only anatomical sacral parameter studied that differed significantly between females and males was the mean APD, which was greater in the older group (Table V).

Table 3. - Mean \pm SD values of the anatomical parameters in each group by age and sex

\begin{tabular}{|l|c|c|c|c|c|c|}
\hline & $\begin{array}{c}\text { Females }<10 \mathrm{y} \\
(\mathrm{n}=20)\end{array}$ & $\begin{array}{c}\text { Males }<10 \mathrm{y} \\
(\mathrm{n}=20)\end{array}$ & $p$ value & $\begin{array}{c}\text { Females } \geq 10 \mathrm{y} \\
(\mathrm{n}=20)\end{array}$ & $\begin{array}{c}\text { Males } \geq 10 \mathrm{y} \\
(\mathrm{n}=20)\end{array}$ & $p$ value \\
\hline PIP $(\mathrm{mm})$ & $84.5 \pm 7.9$ & $88.8 \pm 4.7$ & 0.17 & $100.9 \pm 5.1$ & $95.3 \pm 31.4$ & 0.36 \\
\hline PSJ $(\mathrm{mm})$ & $45.7 \pm 3.9$ & $50.4 \pm 4.1$ & 0.01 & $52.3 \pm 5.8$ & $55.5 \pm 6.9$ & 0.27 \\
\hline LD $(\mathrm{mm})$ & $33.1 \pm 3.1$ & $31.6 \pm 4.3$ & 0.40 & $32.6 \pm 2.7$ & $29.0 \pm 2.7$ & 0.008 \\
\hline
\end{tabular}

PIP, distance between the two posterior iliac processes ; PSJ, distance between the two posterior sacral joints ; LD, lateral (side-to-side) diameter of the spinal canal ; APD, antero-posterior diameter of the spinal canal. 
For all study parameters, the ICC was $\geq 0.8$, indicating good or very good intra- and interobserver agreement. The Bland-and-Altmann plots showed good agreement between observers, with no outliers.

\section{DISCUSSION}

Pelvic fixation as part of the treatment of spinal deformities continues to raise technical challenges due to the convoluted anatomy of the pelvic bones and wide inter-individual variations in pelvic anatomy. An additional challenge is the frequently poor bone quality in paediatric patients with spinal deformities. Thus, mechanical complications are common. Ilio-sacral screw implantation has been found to provide reliable and strong fixation with a low rate of complications (5-6-7), provided the screw is properly positioned (Figure 8). Screw malposition is a dreaded complication associated with potentially severe injuries to blood vessels and nerves (8-9). More specifically, the S1 root can be damaged if the screw enters the sacral foramen. To decrease the risk of injury, secure corridors for screw insertion have been defined in adults (10). Here, we defined the secure corridor for ilio-sacral screw insertion in paediatric patients. The values found in our study are consistent with those reported for adults in a similar CT study (11).

We compared the optimal screw insertion angle in patients younger and older than 10 years and in females vs. males. The mean optimal angle did not differ between males and females. Although differences in anatomical sacral parameters were noted across the groups defined by age and sex, none was large enough to substantially affect the optimal screw insertion angle.

Factors assumed to influence the accuracy of screw positioning include age, sex, body mass index, and number of screws. In a study of adults with pelvic injuries, screw malposition was slightly more common in patients with obesity, presumably due to poorer intra-operative visibility (12). Screw malposition was more common with two screws than with a single screw, whereas age, sex, angle between the screw and S1 endplate, type of sacral fracture, and severity of injury were not significantly

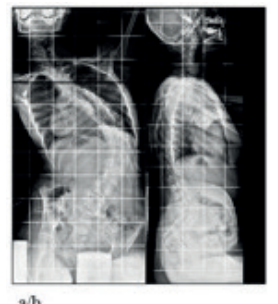

$\mathrm{a} b$

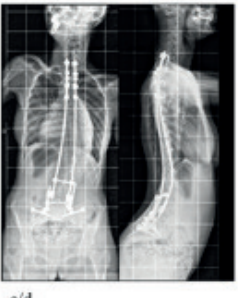

e/d

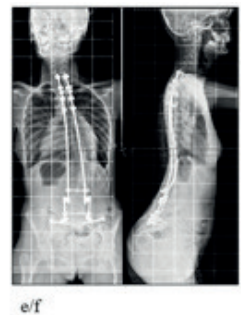

Fig. 8a-f. - Radiographic illustrations of a 11 years-old girl with Rett syndrom. a/b : Pre-operative X-Rays. c/d : X-rays after 18 months follow-up (before rod lengthening). e/f : X-rays 2.5 years after rod lengthening.

associated with accuracy of screw positioning (11). In a CT study of 100 adults with spinal deformities, the optimal trajectory of S2 alar-iliac screws was not different between males and females (13).

A study of CT scans from 30 adults assessed variations in upper sacral anatomy according to various factors (14). Age was not associated with variability. Overall, differences according to sex, height, and weight were small. A model for ilio-sacral screw insertion in the prone position proved reliable and reproducible independently of the factors studied. This model involved placing the connector between the screw and the spinal instrumentation, near the entry point of the S1 pedicular screw. Three points were also used in this model: point $\mathrm{A}$ is exposed during the surgical approach and therefore does not require localisation by navigation or fluoroscopy ; point B is at the junction of the anterior and middle thirds of the sacral endplate, where density of the sacral trabecular bone is greatest (15); and point $\mathrm{C}$ is at the intersection of the $\mathrm{AB}$ line with the external facet of the iliac wing .

In a retrospective review of 28 consecutive adults with a mean follow-up after ilio-sacral screw fixation of 3.5 years, no neurological complications were recorded (16). Radiographic evidence of fusion was seen in $95 \%$ of patients. Of the 28 patients, 23 had a history of non-union after previous surgery, suggesting that ilio-sacral screw fixation may be a valid alternative after failure of other lumbar-pelvic fixation techniques. Another study assessed radiographic outcomes at least 2 years after ilio-sacral screw fixation in adults with spinal 
deformities (17). No mechanical complications were recorded, and correction was achieved consistently.

The stability of ilio-sacral screws depends on four factors. The screw must have cortical purchase in the inner and outer tables of the ilium and posterior sacrum. The path of the screw must go through the dense trabecular bone just below the S1 endplate and sacral promontory. The screw must be directed perpendicularly to the rod to optimise load-sharing and maximise resistance against the pull-out forces generated by long spinal constructs. Finally, the screw must be directed in a way that stabilises the sacro-iliac joint while preserving its motion.

Percutaneous ilio-sacral screw insertion may decrease the risk of peri-operative complications, such as surgical-site infection, compared to open screw implantation (18). In practice, exposure of the external iliac wing is unnecessary, since the location of the screw entry point in the outer table of the ilium varies with the connector setting and optimal insertion angle in the prone position.

The ilio-sacral screw insertion technique is freehand but can be combined with $\mathrm{CT}$ or navigation (19). However, minimising exposure to ionising radiation is particularly important in paediatric patients. In a study of S2 alar-iliac screw insertion, both a freehand and a robot-guided technique proved safe and reliable (20).

The following limitations should be considered when interpreting our findings. First, the small sample size resulted in limited statistical power. However, the accurate assessment of screw position is the main strength of our investigation. Also, the patients did not have spinal deformities, which are known to alter the anatomical pelvic parameters. Nonetheless, pre-operative CT scans can be used to plan the procedure, including appropriate positioning of the screw. Furthermore, this technique can be used to simplify ilio-sacral fixation in pelvic ring trauma or reconstruction, as well as in spondylolisthesis fixation.

\section{CONCLUSION}

This study provides the first data on optimal ilio-sacral screw positioning in paediatric patients. The optimal insertion angle varied slightly with age $(33.1 \pm 4.3<10 \mathrm{y}$ and $30.0 \pm 4.6>10 \mathrm{y})$, with no difference between females and males. The results of our study should help to achieve safe and easy ilio-sacral screw placement.

\section{REFERENCES}

1. Abdelgawad AA, Davey S, Salmon J, et al. Ilio-sacral screw fixation for sacral and sacroiliac joint injuries in children. J Pediatr Orthop. 2016 ; 36 : 117-21.

2. Cotrel Y, Dubousset J, Guillaumat M, et al. New universal instrumentation in spinal surgery. Clin Orthop Relat Res. $1988 ; 227: 10-23$.

3. Miladi L, Ghanem I, Draoui M. et al. Iliosacral screw fixation for pelvic obliquity in neuromuscular scoliosis. A long-term follow-up study. Spine. 1997 ; 22 : 1722-9.

4. Miladi L, Gaume M, Khouri N, et al. Minimally Invasive Surgery for Neuromuscular Scoliosis: Results and Complications in a Series of One Hundred Patients. Spine.2018; 43 : E968-E975.

5. Wu T, Chen W, Zhang Q, et al. Biomechanical comparison of three types of internal fixation in a type $\mathrm{C}$ zone II pelvic fracture model. Int J Clin Exp Med. 201515 ; 8 : 1853-61.

6. Yinger K, Scalise J, Olson SA et al. Biomechanical comparison of posterior pelvic ring fixation. J Orthop Trauma. $2003 ; 17: 481-7$.

7. Oberkircher L, Masaeli A, Bliemel C, et al. Primary stability of three different iliosacral screw fixation techniques in osteoporotic cadaver specimens-a biomechanical investigation. Spine J. $2016 ; 16: 226-32$.

8. Osterhoff G, Ossendorf C, Wanner GA et al.Percutaneous ilio-sacral screw fixation in s1 and s2 for posterior pelvic ring injuries: technique and perioperative complications. Arch orthop trauma surg. $2011 ; 131: 809-813$.

9. Ziran BH, Smith WR, Towers J et al. Ilio sacral screw fixation of the posterior pelvic ring using local anesthesia and computerized tomography. J Bone Joint Surg Br. 2013 ; $85: 411-418$

10. Mendel T, Radetzki F, Wohl D. et al. CT-based 3-D visualization of secure bone corridors and optimal trajectories for sacroiliac screws. Injury 2013 ; 44 : 957-963.

11. Sun X, Li S, Qiu Y. et al. Anatomical Study of a Novel Ilio sacral Screw Placement for Sacrum-Pelvis in Adult via Computed Tomography Reconstruction. Spine 2018; 43 : E740-E745.

12. Pishnamaz M, Dienstknecht T, Hoppe B. et al. Assessment of pelvic injuries treated with ilio sacral screws : injury severity and accuracy of screw positioning. International orthopaedics. $2016 ; 40: 1495-1501$.

13. Weisenthal BM, Doss DJ, Henry AL. et al. Optimal trajectory and length of S2 alar iliac screws : A 3D computed aided design study. Clin Spine Surg. $2019 ; 100$.

14. Dubory A, Bouloussa H, Riouallon $\mathbf{G}$ et al. A computed tomographic anatomical study of the upper sacrum. 
Application for a user guide of pelvic fixation with ilio sacral screws in adult spinal deformity. Int Orthop. 2017 ; $41: 2543-2553$.

15. Peretz AM, Hipp JA, et al. The internal bony architecture of the sacrum. Spine. $1998 ; 1: 23: 971-4$.

16. Farcy JP, Rawlins BA, Glassman SD. et al. Technique and results of fixation to the sacrum with iliosacral screws. Spine. 1992 ; 17 (6 Suppl) : S190-5.

17. Ould-Slimane M, Miladi L, Rousseau MA. et al. Sacro pelvic fixation with ilio sacral screws: applications and results in adult spinal deformities. J Spinal Disord Tech. $2013 ; 26: 212-7$.
18. Wolff S, Habboubi K, Sebaaly A. et al. Correction of adult spinal deformity with a minimally invasive fusionless bipolar construct : Preliminary results. Orthop Traumatol Surg Res. 2019 ; 105 : 1149-1155.

19. Zwingmann J, Konrad G, Mehlhorn A. et al. Percutaneous ilio sacral screw insertion: malpositioning and revision rate of screws with regards to application techniques (navigates vs. conventional). The J Trauma. 2010 ; 69 : 1501-1506.

20. Laratta J, Shillingford JN, Meredith JS. et al. Robotic versus freehand S2 alar iliac fixation: in depth technical considerations. Journal of Spine Surgery. 2018 ; 4 : 638644. 